\title{
C-reactive protein, obesity, atopy and asthma symptoms in middle-aged adults
}

\author{
B.K. Butland, D.P. Strachan and A.R. Rudnicka
}

\begin{abstract}
Recent research has suggested an association between circulating C-reactive protein (CRP) and adult asthma, confined to those without evidence of allergic predisposition. The current authors investigated the role of smoking and obesity as possible explanations for this relationship.
\end{abstract}

At 44-45 yrs of age, members of the British 1958 birth cohort participated in a biomedical survey involving the measurement of the following: CRP; the specific immunoglobulin $E$ to grass, cat and dust mite; standing height; and weight. Information on asthma and related symptoms was collected by computer-aided interview when the subjects were 42 yrs of age. Complete data were available for a total of 6,490 subjects.

CRP levels were positively correlated with the body mass index (BMI) and were found to be higher among females when compared with males, and higher among heavy smokers ( $\geqslant 20$ cigarettes $\cdot$ day $^{-1}$ ) when compared with never-smokers. After adjustment for sex and region, the odds ratios, comparing asthma prevalence in subjects above the fourth CRP quartile with subjects below the first quartile, were 1.85 (95\% confidence interval 1.15-2.99) for nonatopics and $0.94(0.62-1.41)$ for atopics, changing to $1.36(0.80-2.32)$ and $1.07(0.67-1.69)$, respectively, when additionally adjusted for smoking and BMI.

Any association between C-reactive protein and asthma prevalence confined to nonatopics may be due to confounding factors. Alternatively, it may reflect a more general association of $\mathrm{C}$ reactive protein with smoking-related obstructive airways disease.

KEYWORDS: Asthma, atopy, body mass index, C-reactive protein

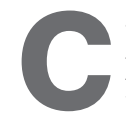

-reactive protein (CRP) is an acute phase protein produced in the liver in response to infection and tissue damage under the control of interleukin-6, tumour necrosis factor- $\alpha$ and other cytokines [1, 2]. With the introduction of highly sensitive assays, CRP has been used in epidemiological studies as a marker for lowgrade systemic inflammation [1, 2]. Positive associations of CRP levels with chronic obstructive pulmonary disease (COPD) [3-6], wheezing illness and asthma [1, 7], and an inverse association with lung function (forced expiratory volume in one second) [2, 8, 9], suggest that systemic inflammation may play a role in the pathogenesis of respiratory illness. However, a recent analysis of Icelandic and Scandinavian data from the second European Community Respiratory Health Survey, which reported a positive association between CRP and nonallergic asthma, found no evidence of a similar association with allergic asthma [1]. This argues against a general role for CRP and implies that these two asthma phenotypes may differ in terms of causal factors and pathogenesis [1]. However, confounding and reverse causation are possible alternative explanations for the association of CRP with nonatopic asthma. The current authors investigated these issues using data from the British 1958 birth cohort, adjusting for sex, body mass index (BMI), smoking and socioeconomic status in childhood and comparing the association of CRP with asthma prevalence at 42 yrs of age between atopic and nonatopic subjects.

\section{MATERIALS AND METHODS \\ Study subjects}

The British 1958 birth cohort $(n=18,558)$ consisted of children born in Britain during one week in 1958 plus immigrants born at the same time and entering the country before their 17th birthday.

\section{Study design}

The cohort has been followed up at various ages $[10,11]$. At 42 yrs of age, 11,419 cohort members [10] were interviewed and information was collected on smoking history and respiratory symptoms. Each cohort member was asked if they had "ever had any wheezing or whistling in
AFFILIATION

Division of Community Health

Sciences, St George's, University of London, London, UK.

CORRESPONDENCE

D.P. Strachan

Division of Community Health

Sciences

St George's

University of London

Cranmer Terrace

Tooting

London SW17 ORE

UK

Fax: 442087253584

E-mail: d.strachan@sgul.ac.uk

Received:

June 252007

Accepted after revision:

February 252008

SUPPORT STATEMENT

The biomedical survey at 44-45 yrs

of age was funded by the Medical

Research Council (London, UK) as

part of the Health of the Public

Initiative grant G0000934.

STATEMENT OF INTEREST

A statement of interest for

B.K. Butland can be found at

www.erj.ersjournals.com/misc/

statements.shtml 
your chest in the past 12 months", whether they had "ever had or been told you had asthma" and if so whether they "had asthma in the last 12 months" [12]. Information on the subject's father's social class was collected at birth by the midwife and later supplemented, where missing, with the father's social class as reported by parents at the 7-yr follow-up [13].

By August 2002, there were 14,737 cohort members living in Great Britain, after excluding permanent refusals. With the exclusion of a further 2,668 subjects for reasons including poor response history, the need for interview by proxy, no current valid address, past threatening behaviour and serving in the armed forces, a final 12,069 cohort members were invited to participate in a biomedical survey at $44-45$ yrs of age [14]. This survey received ethical approval from the South East Research Ethics Committee (formally known as the South East England Multicentre Regional Ethics Committee; Aylesford, Kent, UK; ref. $01 / 1 / 44)$. The response rate among those targeted was $78 \%$ $(n=9,377)$ [14]. Further details of sampling and possible bias are detailed elsewhere [10, 11, 14]. Nurses measured height and weight (estimated if measurement refused) and average systolic blood pressure (mean of three readings) [13] and collected blood samples for biochemical analysis, which included total cholesterol, CRP or and immunoglobulin (Ig) E. Information on current medication, chest infection ("any respiratory infections e.g. influenza, pneumonia, bronchitis or severe cold") in the previous 3 weeks, and asthma medication use ("used an inhaler, puffer or any medication for your breathing") in the last $24 \mathrm{~h}$, was collected contemporaneously as part of a nurseled computer-assisted personal interview [14].

\section{Methods}

The blood samples were separated into tubes and posted from the field, at ambient temperature, to the laboratory at the Royal Victoria Infirmary (Newcastle, UK), where the total $\operatorname{IgE}$ concentration was assayed using the HYTEC automated enzyme immunoassay (Hycor Biomedical Ltd, Penicuik, UK) $[14,15]$. Specific IgE to cat, mixed grasses and house dust mite were also measured if the total $\operatorname{IgE}$ was $>30 \mathrm{kU} \cdot \mathrm{L}^{-1}$, but automatically coded zero if total $\operatorname{IgE}$ was $\leqslant 30 \mathrm{kU} \cdot \mathrm{L}^{-1}[16]$. Atopy was defined as a minimum of one specific IgE level $>0.3 \mathrm{kU} \cdot \mathrm{L}^{-1}$. Citrated plasma produced in the Royal Victoria Infirmary was frozen at $-70^{\circ} \mathrm{C}$ and transported, frozen, to the Dept of Medicine at the University of Glasgow (Glasgow Royal Infirmary, Glasgow, UK), where CRP was measured using nephelometric analysis of latex particles coated in CRP monoclonal antibodies (BN ProSpec protein analyzer; Dade Behring, Marburg, Germany). The quality of CRP measurement was monitored over time using Levey-Jennings plots [14].

\section{Analysis}

The CRP distribution was positively skewed. The 365 values of CRP that were below the detection level of the assay $\left(0.15 \mathrm{mg} \cdot \mathrm{L}^{-1}\right)$ were arbitrarily assigned half this value $\left(0.075 \mathrm{mg} \cdot \mathrm{L}^{-1}\right)$ before being $\log$ transformed. CRP was classified as missing for those cohort members who reported a chest infection in the 3 weeks prior to giving a blood sample.

A series of logistical regression analyses, adjusted for sex and region of residence at $44-45 \mathrm{yrs}$ of age, were used to investigate the association of log CRP with the prevalence of asthma in the previous 12 months, as reported at 42 yrs of age (primary outcome) and the prevalence of "wheeze without asthma" over the same period. Wheeze without asthma was defined as a report of wheezing or whistling in the chest in the past 12 months without a report of asthma in the previous 12 months. Models including and excluding a CRP/atopy interaction term were compared using the likelihood ratio test to detect differences in association between atopic and nonatopic subjects. Potential confounding by BMI, smoking history and father's social class was adjusted for by including these variables in the model, along with their atopy interaction terms. However, when investigating the association of BMI with the prevalence of asthma and wheeze without asthma, models were fitted that adjusted for father's social class and smoking history (including their interactions with atopy), sex and region but not CRP.

The association of log CRP with BMI, smoking history, father's social class and sex was modelled using mixed effects regression in the statistical system used, adjusting for the postal delay in processing blood samples and the hour in which the blood was taken as fixed effects and CRP batch as a random effect [17].

For ease of presentation, CRP and BMI were sometimes tabulated as four level factors, defined by their respective quartiles. However, the continuous variables, or in the case of CRP the log of the continuous variable, were always used for significance tests and when adjusting for their effects as potential confounders, unless otherwise stated.

\section{RESULTS}

\section{Sample attrition}

The self-reported prevalence of asthma at $42 \mathrm{yrs}$ of age in the 11,376 subjects investigated was $684(6 \%)$. Out of these 11,376 subjects a total of 6,490 had complete data on the following: atopy, CRP, sex, smoking, BMI, region and father's social class. Among those with complete data $(n=6,490)$, the self-reported prevalence of asthma and wheeze without asthma was 5.6 and $12.2 \%$, respectively. Among the remaining subjects $(n=4,886)$, prevalence of asthma and wheeze without asthma was 6.5 and $14.9 \%$, respectively. After the 871 individuals, who had reported a chest infection in the 3 weeks prior to giving a blood sample, were excluded these values fell to 5.7 and $14.4 \%$, respectively.

\section{Asthma}

Asthma prevalence as reported at 42 yrs of age was higher in females than in males among atopic (16.1 versus 9.7\%) and nonatopic subjects (4.7 versus $2.4 \%$ ). In preliminary analyses adjusted for sex, atopy and region, asthma prevalence was significantly and positively associated with CRP and BMI. In both cases the association differed significantly between those with and without atopy (table 1).

\section{Smoking}

For smoking there was no evidence of an overall association with asthma prevalence. However, among nonatopics, prevalence appeared to increase with the amount currently smoked, while among atopics it appeared to decrease and this difference was highly, statistically significant. A similar, although less marked, contrast was observed for father's social class. 
TABLE 1 The prevalence of asthma at $42 \mathrm{yrs}$ of age among atopics and nonatopics by C-reactive protein (CRP) and other variables of interest

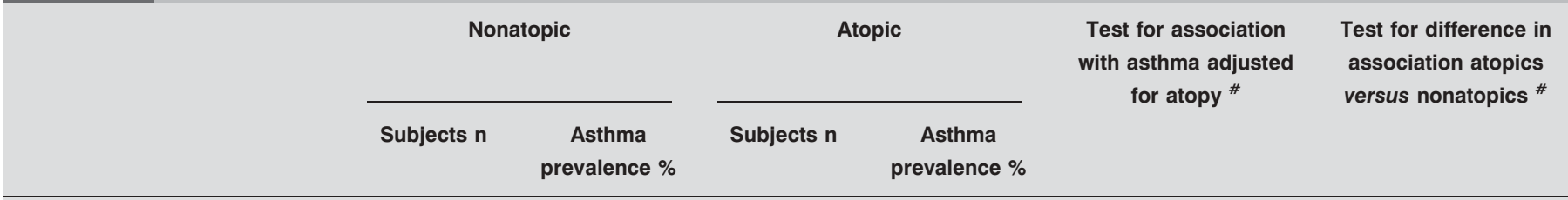

\section{CRP $\mathrm{mg} \cdot \mathrm{L}^{-1}$ \\ $<0.454$ \\ $0.454-0.937$ \\ $0.938-2.12$ \\ $>2.12$}

BMI $\mathbf{k g} \cdot \mathrm{m}^{-2}$

$<23.99$

23.99-26.69

26.69-29.92

$>29.92$

Smoking history at $\mathbf{4 2}$ yrs of age

Never-smoker

Ex-smoker

$<1$ cigarette $\cdot$ day $^{-1}$

$\geqslant 1$ cigarette $\cdot$ day $^{-1}>5$ yrs ago

$\geqslant 1$ cigarette $\cdot$ day $^{-1} \leqslant 5$ yrs ago

Current smoker

$<1-9$ cigarette $\cdot$ day $^{-1}$

10-20 cigarette $\cdot$ day $^{-1}$

$\geqslant 20$ cigarette $\cdot$ day $^{-1}$

\section{Father's social class at birth}

Professional I

Managerial or technical II

Other nonmanual IIInm

Skilled manual IIIm

Partly skilled IV

Unskilled manual $\mathrm{V}$

Other or unknown or unemployed

Medication for breathing taken

$24 \mathrm{~h}$ prior to giving a blood

sample

Yes

No or missing

$1209 \quad 2.2$

$1161 \quad 2.7$

$1150 \quad 3.9$

$1165 \quad 4.3$

$1410 \quad 3.1$

$1349 \quad 2.9$

$1300 \quad 3.2$

$1245 \quad 5.2$

$2399 \quad 2.8$

287

855

242

385

483

659

251

701

517

2571

672

421

182

156

5159
$2.2 \quad 440$

463

470

470
455

$455 \quad 11.6$

$462 \quad 12.6$

$548 \quad 13.0$

$558 \quad 12.0$

$565 \quad 12.0$

$1008 \quad 13.0$

$132 \quad 15.2$

$335 \quad 14.9$

$80 \quad 16.3$

$\begin{array}{ll}164 & 9.8\end{array}$

$188 \quad 8.5$

$227 \quad 7.5$

$114 \quad 20.2$

$336 \quad 10.1$

$212 \quad 13.2$

$996 \quad 13.1$

$226-10.6$

$\begin{array}{ll}156 & 7.7\end{array}$

$98 \quad 13.3$

12.5

0.4

5

13.3
2.1

6
.

0

\section{.0}

9

p $=0.60^{+} \quad p<0.001^{+}$

8

0.1

$1 \quad p=0.68^{+} \quad p=0.042^{+}$

$211 \quad 67.8 \quad p<0.001^{\circ} \quad p=0.19^{\circ}$

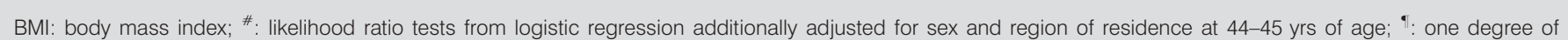
freedom; ${ }^{+}$: six degrees of freedom.

\section{C-reactive protein}

CRP levels were independently positively associated with being female, higher BMI, current smoking, poorer socioeconomic status in childhood and self-reported use of an inhaler, puffer or other medication for breathing in the $24 \mathrm{~h}$ prior to giving a blood sample (table 2).

\section{Asthma and C-reactive protein}

Table 3 shows the effect of adjusting the CRP-asthma association for correlates of CRP. Following adjustment for smoking history and BMI, in addition to sex and region of residence, the association between CRP and asthma prevalence lost significance, as did the difference in association between atopics and nonatopics. Further analyses suggested that BMI and smoking history were equally important confounders in this respect (data not shown). Further adjustment for father's social class had little effect (table 3), as did the inclusion of a sex-atopy interaction term along with correlates of ischaemic heart disease (i.e. average systolic blood pressure, total cholesterol and reported use of medication for blood pressure or heart problem and their atopy interactions (data not shown)).

\section{Confounding by smoking}

Figure 1 shows the prevalence of asthma stratified by atopy and smoking. This illustrates the much higher prevalence of asthma among atopics than nonatopics but of particular 


\begin{tabular}{|c|c|c|}
\hline \multirow[t]{2}{*}{ TABLE 2} & \multirow[b]{2}{*}{ Change in geometric mean of CRP } & \multirow[b]{2}{*}{ p-value } \\
\hline & & \\
\hline BMI per $5 \mathrm{~kg} \cdot \mathrm{m}^{-2}$ higher & $73(69-78)$ & $p<0.001$ \\
\hline Female versus male & $15(9-21)$ & $\mathrm{p}<0.001$ \\
\hline \multicolumn{3}{|l|}{ Smoking history at 42 yrs versus never smoked } \\
\hline$\geqslant 1$ cigarette $\cdot$ day $^{-1}>5$ yrs ago & $5(-3-12)$ & \\
\hline$\geqslant 1$ cigarette $\cdot$ day $^{-1} \leqslant 5$ yrs ago & $11(-2-26)$ & \\
\hline Current smoker & & $\mathrm{p}<0.001$ \\
\hline$<1-9$ cigarette $\cdot$ day $^{-1}$ & $21(9-33)$ & \\
\hline $10-20$ cigarette $\cdot$ day $^{-1}$ & $50(37-65)$ & \\
\hline Skilled manual IIIm & $14(2-29)$ & $p=0.002$ \\
\hline Partly skilled IV & $8(-6-23)$ & \\
\hline Unskilled manual V & $13(-2-30)$ & \\
\hline Other or unknown or unemployed & $13(-5-34)$ & \\
\hline Medication for breathing taken $24 \mathrm{~h}$ prior to giving a blood sample yes versus no or missing & $19(5-35)$ & $p=0.005$ \\
\hline
\end{tabular}

Data are presented as per cent (95\% confidence interval), unless otherwise stated. BMI: body mass index. ${ }^{*}$ : also adjusted for delay in processing bloods, the hour in which the blood sample was taken and CRP batch (as a random effect); $\bullet: n=6,718$.

interest is the lack of a positive association between prevalence and CRP in the never-smokers.

In terms of sensitivity analyses the present authors also investigated the effect on the final model shown in table 3 using a simpler form of smoking variable (never-smoker, exsmoker, current smoker) and using a more complex form of adjustment for smoking that included linear terms for both the number of cigarettes smoked by current smokers and the age of quitting, as reported by ex-smokers. In both cases the current results changed little. The odds ratios (OR $(95 \%$ confidence interval)) comparing those greater than the fourth CRP quartile with those below the lower quartile for atopics and nonatopics, respectively, were $1.07(0.67-1.70)$ and 1.39 $(0.82-2.38)$ using the simple adjustment and $1.07(0.67-1.70)$ and $1.39(0.81-2.38)$ using the more complex adjustment.

TABLE 3 Adjusted odds ratios describing the association of C-reactive protein (CRP) with the prevalence of asthma at $42 \mathrm{yrs}$ of age among those with" and without" atopy

\begin{tabular}{|c|c|c|c|c|c|c|}
\hline & \multicolumn{2}{|c|}{ Model $1^{+}$} & \multicolumn{2}{|c|}{ Model $2^{\S}$} & \multicolumn{2}{|c|}{ Final model ${ }^{f}$} \\
\hline & Nonatopic & Atopic & Nonatopic & Atopic & Nonatopic & Atopic \\
\hline$<0.454$ & 1.00 (baseline) & 1.00 (baseline) & 1.00 (baseline) & 1.00 (baseline) & 1.00 (baseline) & 1.00 (baseline) \\
\hline $0.454-0.937$ & $1.25(0.74-2.10)$ & $0.87(0.57-1.31)$ & $1.16(0.68-1.96)$ & $0.91(0.59-1.39)$ & $1.19(0.70-2.01)$ & $0.90(0.59-1.38)$ \\
\hline $\begin{array}{l}\text { Test for association } \\
\text { with asthma } \\
\text { adjusted for atopy }\end{array}$ & $p=0.030$ & & $p=0.11$ & & $p=0.12$ & \\
\hline $\begin{array}{l}\text { Test for difference in } \\
\text { association atopics } \\
\text { versus nonatopics }\end{array}$ & $p=0.023$ & & $p=0.49$ & & $p=0.44$ & \\
\hline
\end{tabular}

Data are presented as odds ratio (95\% confidence intervals), unless otherwise stated. ${ }^{\#}: \mathrm{n}=1,820 ;{ }^{\bullet}: \mathrm{n}=4,670 ;{ }^{+}:$adjusted for atopy, sex and region of residence; ${ }^{\varsigma}$ : adjusted as in model 1 with additional adjustment for smoking history and body mass index; ${ }^{f}$ : adjusted as in model 2 with additional adjustment for father's social class. 

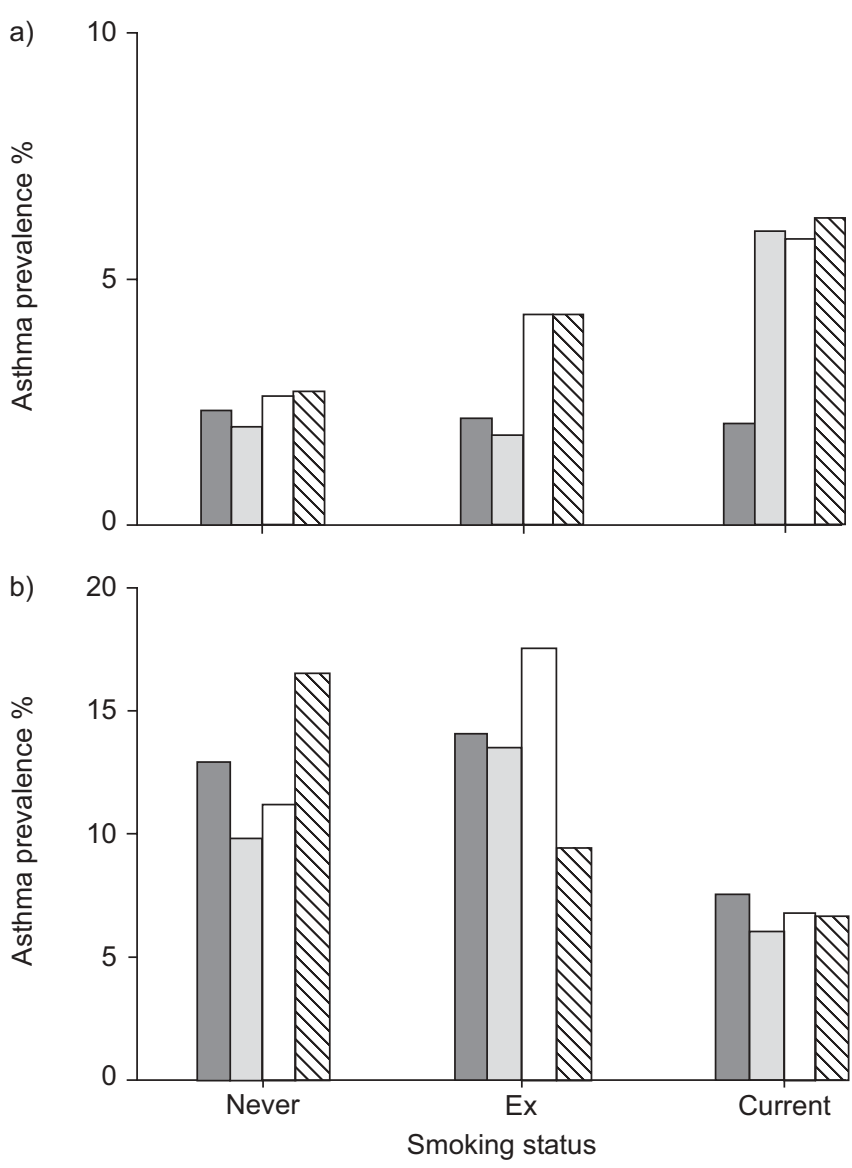

FIGURE 1. The association between asthma prevalence in a) nonatopic and b) atopic subjects at $42 \mathrm{yrs}$ of age, their smoking status and the concentration of Creactive protein $\left(\mathrm{mg} \cdot \mathrm{L}^{-1}\right)$ : $\mathbf{\square}:<0.454 ; \mathbf{\square}: 0.454-0.937 ; \square: 0.938-2.12 ; \mathbb{\mathbb { N }}:>2.12$.

\section{Confounding by BMI}

In contrast, when the current authors added a quadratic term in BMI to the final model in table 3, to allow for nonlinearity in the BMI asthma prevalence association, the OR comparing those above the upper quartile with those below the lowest quartile of CRP changed little for atopics (1.05 (0.66-1.67)) but increased for nonatopics (1.50 (0.87-2.58)). However, both an overall association between CRP and asthma prevalence and any difference in association between atopics and nonatopics remained nonsignificant, $\mathrm{p}=0.104$ and $\mathrm{p}=0.378$, respectively. Similar results were obtained $(p=0.081$ and $p=0.244$, respectively) when BMI was adjusted for as a 10 level factor (defined by deciles). ORs contrasting those above the upper quartile with those below the lowest were $1.05(0.66-1.67)$ for atopics and 1.56 (0.91-2.67) for nonatopics.

\section{Asthma and BMI}

The overall positive association between BMI and asthma prevalence observed in table 2 persisted after the additional adjustment for smoking history and father's social class $(p=0.010)$, as did evidence of a difference in this association between atopic and nonatopic subjects $(p=0.015)$. The adjusted ORs contrasting those above the highest BMI quartile with those below the lowest were $1.06(0.72-1.56)$ for atopics and $1.90(1.27-2.82)$ for nonatopics.

\section{Wheeze without asthma}

When the present authors repeated the analyses for wheeze without asthma, a different pattern of association was observed (table 4).

Having adjusted for sex, atopy and region, the prevalence of wheeze without asthma was significantly higher among current cigarette smokers compared with ex-smokers and the never-smokers and among those from a lower compared with a higher social class background in childhood. There were also significant positive associations with CRP and BMI. However, only the association with BMI differed significantly between atopic and nonatopic subjects. When adjusted for smoking history (the more complex form of adjustment), BMI and father's social class, the association with CRP was considerably weakened and only just remained statistically significant $(p=0.04)$. In contrast, the association with BMI persisted after adjustment for smoking history and father's social class $(p<0.001)$, as did evidence of a difference in association between atopics and nonatopics $(p=0.018)$. The adjusted ORs contrasting those above the highest quartile of BMI with those below the lowest quartile were $0.99(0.71-1.39)$ for atopics and 1.93 (1.50-2.49) for nonatopics.

\section{Response bias}

The mean \pm SD BMI was higher among those with missing information on atopy $28.0 \pm 5.7$ versus those with usable information on $27.3 \pm 4.9 \mathrm{~kg} \cdot \mathrm{m}^{-2}$. When the present authors included rather than excluded such subjects, the crude ORs contrasting those above the upper quartile of BMI with those below the lower quartile were 1.47 for asthma (increased from 1.38), and 1.48 for wheeze without asthma (decreased from 1.59). This suggested that although the current analyses tended to underestimate the overall association between BMI and asthma prevalence and overestimate the overall association between BMI and wheeze without asthma, these biases were relatively small.

\section{DISCUSSION}

In common with other studies, the present authors found that CRP was positively associated with obesity $[1,2,5,6,9,18,19]$ and smoking $[1,2,6]$. Levels of CRP were also found to be higher among females than males [19] and among those with fathers in manual rather than nonmanual occupations $[2,6]$. In preliminary analyses, adjusted only for sex, atopy and region of residence, there was evidence of a positive association between CRP and the prevalence of asthma at 42 yrs of age, an association which appeared to be confined to nonatopics. This was in keeping with the recent findings by ÓLAFSDOTTIR et al. [1], who suggested, based on data from the European Community Respiratory Health Study, that CRP was positively associated with nonallergic asthma but not with allergic asthma. However, when the current authors further adjusted for BMI and smoking, both the overall association between CRP and asthma prevalence and any difference in association between atopics and nonatopics lost statistical significance. No evidence of an atopy-CRP interaction was observed for wheeze without asthma.

The importance of smoking as a potential confounder was highlighted in the current data by the lack of evidence for an association between CRP and asthma prevalence among 


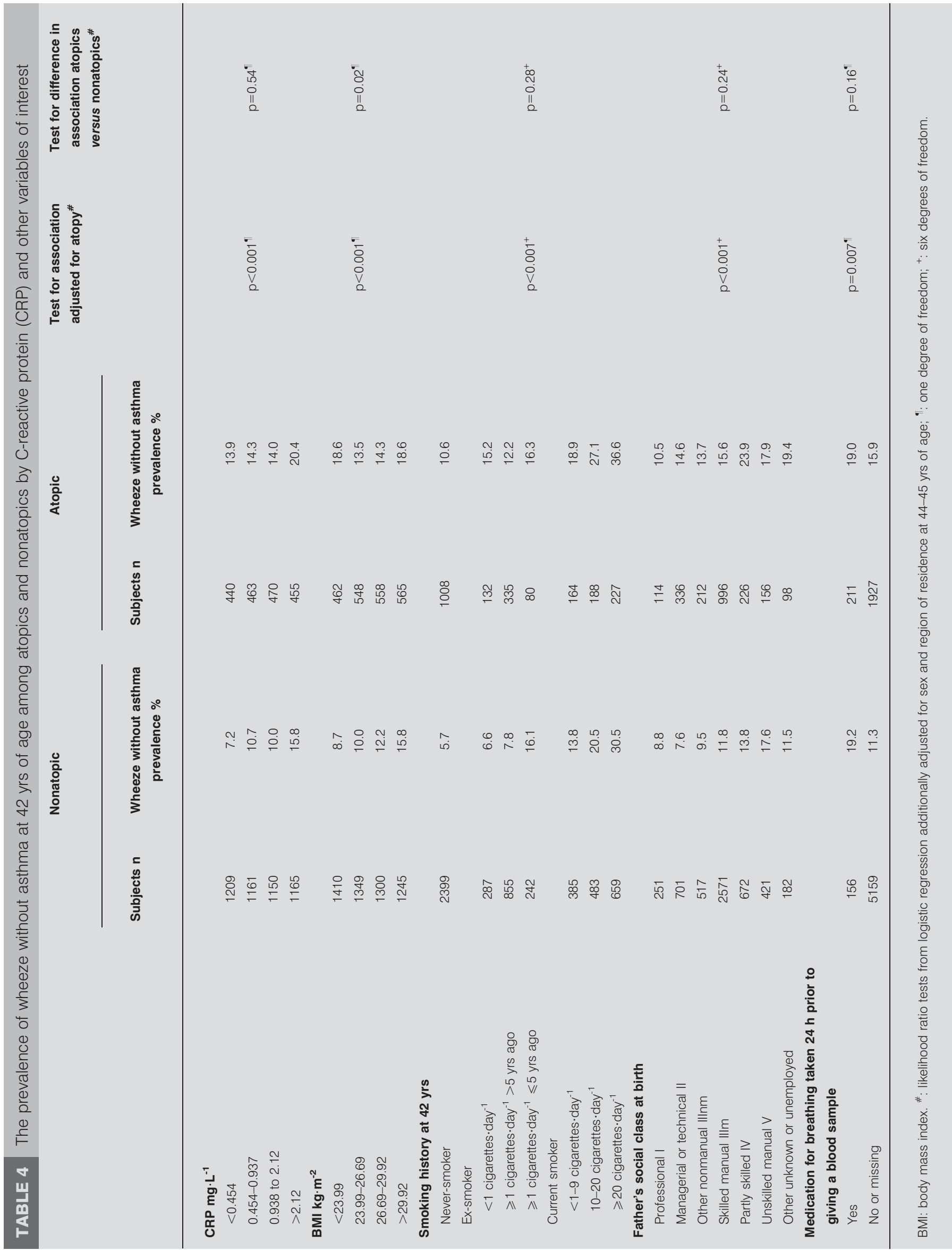


lifelong nonsmokers (fig. 1). Furthermore, an increasing trend in asthma prevalence with the amount smoked was only found among nonatopics, whereas there was a decreasing trend with the amount currently smoked among atopics. Evidence for a positive association between smoking and asthma confined to nonatopics comes from a large study of young Spanish adults [20] that investigated the relationship between smoking and bronchial hyperresponsiveness.

Of equal importance, in terms of confounding was BMI, the exact nature of the association between BMI and asthma prevalence is not clear [21-22], although the present study's analyses suggested that any association was confined to nonatopics and that within this group, asthma prevalence was highest among the obese (table 1). Similar associations were observed for wheeze without asthma. This is in keeping with the findings of SCHACHTER et al. [21], who reported positive associations between severe obesity and recent asthma but no evidence of a similar relationship with atopy. However, these findings are in contrast with those of ÓlAFSDOTTIR et al. [1], who reported positive associations between obesity and both allergic and nonallergic asthma, the latter losing significance after adjustment for CRP. In addition the findings of SCHACHTER et al. [21] also contrast with large studies of Swedish male conscripts where a positive relationship with obesity was reported for both asthma with and asthma without rhinoconjunctivitis [23]. Nevertheless, the similarity of associations with BMI that the present authors observed for both asthma and wheeze without asthma does suggest that, should BMI have a role in the development or persistence of wheezing illness, this role may be confined to a type of disease that is unassociated with allergy. Whether pro-inflammatory cytokines mediate any association between BMI and wheezing illness requires further investigation [24].

The role of asthma medication (inhaler, puffer or any medication for breathing) in explaining any association between CRP and wheezing illness is difficult to assess. SIN et al. [25] and PINTO-PLATA et al. [3] found inverse associations between CRP and corticosteroids in patients with COPD; in contrast, the present authors detected a positive association between CRP and reported the use of asthma medication in subjects $24 \mathrm{~h}$ prior to giving a blood sample. These findings may suggest that any steroid-related suppression of CRP levels is being outweighed by a strong association between medication use and more severe forms of respiratory disease, including severe asthma and COPD. Alternatively, it is possible that medication may simply be acting as a marker for minor infections, such as mild-to-moderate colds.

In the current study's final analysis, having adjusted for sex, atopy, region, BMI, smoking history and father's social class, there was still some suggestion of a graded relationship between asthma prevalence and CRP and a pattern of higher OR among nonatopics, although associations were no longer statistically significant. Based on the study's sensitivity analyses, residual confounding by ischaemic heart disease or by amount currently smoked seems an unlikely explanation of any remaining pattern and the misspecification of the BMI and asthma association in the model may have resulted in some over-adjustment for confounding rather than any underadjustment. However, the current authors found no evidence of a CRP-asthma association among lifelong never-smokers. Thus, the possibility of residual confounding by length of time smoked among current smokers cannot be totally discounted. Given that such residual confounding may be more important in a study covering a wide age group compared with a study involving a birth cohort, it could help explain the difference between the current findings and those of ÓLAFSDOTTIR et al. [1].

An alternative explanation for any observed pattern between asthma prevalence and C-reactive protein among nonatopics is possible comorbidity with chronic obstructive pulmonary disease, a disease known to be associated with raised Creactive protein [3-6], or the misdiagnosis of smoking-related chronic obstructive pulmonary disease as asthma among older subjects [26]. Further studies should explore whether or not a C-reactive protein-atopy interaction exists for asthma in children and young adults, where smoking-related chronic bronchitis is less likely to occur or to overlap with nonatopic asthma.

\section{ACKNOWLEDGEMENTS}

The biomedical survey would not have been possible without the continued participation and good will of the members of the British 1958 birth cohort. The authors would, therefore, like to extend their thanks to all the members and to all those involved in the data collection and processing. In particular, the authors would like to thank the laboratory staff, under the leadership of G. Lowe and A. Rumley, at the Dept of Medicine, University of Glasgow (Glasgow Royal Infirmary, Glasgow, UK), who were responsible for measuring the C-reactive protein. The authors would also like to thank the laboratory staff, under the leadership of I. Gibb, at the Royal Victoria Infirmary (Newcastle, UK), who were responsible for measuring the total and specific immunoglobulin E.

\section{REFERENCES}

1 Ólafsdottir IS, Gislason T, Thjodleifsson B, et al. C-reactive protein levels are increased in non-allergic but not allergic asthma: a multicentre epidemiological study. Thorax 2005; 60: 451-454.

2 Mendall MA, Strachan DP, Butland BK, et al. C-reactive protein: relation to total mortality, cardiovascular mortality and cardiovascular risk factors in men. Eur Heart J 2000; 21: 1584-1590.

3 Pinto-Plata VM, Müllerova $\mathrm{H}$, Toso JF, et al. C-reactive protein in patients with COPD, control smokers and nonsmokers. Thorax 2006; 61: 23-28.

4 Yende S, Waterer GW, Tolley EA, et al. Inflammatory markers are associated with ventilatory limitation and muscle dysfunction in obstructive lung disease in well functioning elderly subjects. Thorax 2006; 61: 10-16.

5 Gan WQ, Man SFP, Senthilselvan A, Sin DD. Association between chronic obstructive pulmonary disease and systemic inflammation: a systematic review and a metaanalysis. Thorax 2004; 59: 574-580.

6 Mendall MA, Patel P, Ballam L, Strachan D, Northfield TC. C-reactive protein and its relation to cardiovascular risk factors: a population based cross sectional study. BMJ 1996; 312: 1061-1065. 
7 Sävykoski T, Harju T, Paldanius M, et al. Chlamydia pneumoniae infection and inflammation in adults with asthma. Respiration 2004; 71: 120-125.

8 Sin DD, Man SF. Skeletal muscle weakness, reduced exercise tolerance, and COPD: is systemic inflammation the missing link? Thorax 2006; 61: 1-3.

9 Kony S, Zureik M, Driss F, Neukirch C, Leynaert B, Neukirch F. Association of bronchial hyperresponsiveness and lung function with C-reactive protein (CRP): a population based study. Thorax 2004; 59: 892-896.

10 Power C, Elliott J. Cohort profile: 1958 British birth cohort (National Child Development Study). Int J Epidemiol 2006; 35: 34-41.

11 Hawkes D, Plewis I. Modelling non-response in the National Child Development Study. JR Stat Soc Ser A 2006; 169: 479-491.

12 Bynner J, Butler N, Ferri E, Shepherd P, Smith K. Working Paper 1: The Design and conduct of the 1999-2000 Surveys of the National Child Development Study and the 1970 British Cohort study. Centre for Longitudinal Studies. London, Institute of Education University of London, 2000.

13 Power C, Atherton K, Strachan DP, et al. Life-course influences on health in British adults: effects of socioeconomic position in childhood and adulthood. Int $J$ Epidemiol 2007; 36: 532-539.

14 Fuller E, Power C, Shepherd P, Strachan DP. Technical report on the National Child Development Study biomedical survey 2002-2004. www.b58cgene.sgul.ac.uk/report.php Date last updated: February 28, 2008. Date last accessed: January 27, 2008.

15 Nolte H, DuBuske LM. Performance characteristics of a new automated enzyme immunoassay for the measurement of allergen-specific IgE: summary of the probability outcomes comparing results of allergen skin testing to results obtained with the HYTEC system and CAP system. Ann Allergy Asthma Immunol 1997; 79: 27-34.

16 Butland BK, Strachan DP. Asthma onset and relapse in adult life: the British 1958 birth cohort study. Ann Allergy Asthma Immunol 2007; 98: 337-343.
17 Rudnicka AR, Rumley A, Lowe GD, Strachan DP. Diurnal, seasonal, and blood-processing patterns in levels of circulating fibrinogen, fibrin D-dimer, C-reactive protein, tissue plasminogen activator, and von Willebrand factor in a 45-year-old population. Circulation 2007; 115: 996-1003.

18 Broekhuizen R, Wouters EF, Creutzberg EC, Schols AM. Raised CRP levels mark metabolic and functional impairment in advanced COPD. Thorax 2006; 61: 17-22.

19 Raitakari M, Mansikkaniemi K, Marniemi J, Viikari JSA, Raitakari OT. Distribution and determinants of serum high-sensitive C-reactive protein in a population of young adults: the cardiovascular risk in young Finns study. J Intern Med 2005; 258: 428-434.

20 Sunyer J, Antó JM, Kogevinas M, Soriano JB, Tobías A, Muñoz A. Smoking and bronchial responsiveness in non-atopic and atopic young adults. Spanish Group of the European Study of Asthma. Thorax 1997; 52: 235-238.

21 Schachter LM, Salome CM, Peat JK, Woolcock AJ. Obesity is a risk factor for asthma and wheeze but not airway hyperresponsiveness. Thorax 2001; 56: 4-8.

22 Chinn S. Obesity and asthma: evidence for and against a causal relation. J Asthma 2003; 40: 1-16.

23 Bråbäck L, Hjern A, Rasmussen F. Body mass index, asthma and allergic rhinoconjunctivitis in Swedish conscripts-a national cohort study over three decades. Respir Med 2005; 99: 1010-1014.

24 Franks PW. Obesity, inflammatory markers and cardiovascular diease: distinguishing causality from confounding. J Hum Hypertens 2006; 20: 837-840.

25 Sin DD, Lacy P, York E, Man SF. Effects of fluticasone on systemic markers of inflammation in chronic obstructive pulmonary disease. Am J Respir Crit Care Med 2004; 170: 760-765.

26 Sciurba FC. Physiologic similarities and differences between COPD and asthma. Chest 2004; 126: Suppl. 2, $117 \mathrm{~s}-124 \mathrm{~s}$. 